
Soclety or of tis Divisions or Sections, or printed in tis publications. Discussion is printed onty if the paper is published in an ASME Journal. Authorization to photocopy material for internal or personal use under circumstance not talling within the fair use proviaions of the Copyright Act is granted by ASME to libraries and other users registered with the Copyright Clearmce Center (CCC) Transactional Reporting Service provided that the bese tee of 50.30 per page is peld directly to the CCC, 27 Congress Street. Salem MA 01970. Requests for special permission or bulk reproduction should be eddreesed to the ASME Technical Publishing Department.

\section{SYNCHRONOUS DYNAMICS OF A COUPLED SHAFT/BEARING/HOUSING SYSTEM WITH AUXILIARY SUPPORT FROM A CLEARANCE BEARING: ANALYSIS AND EXPERIMENT}

\author{
James L. Lawen, Jr. \\ Auburn University \\ Auburn, AL 36849 \\ George T. Flowers \\ Auburn University \\ Auburn, AL 36849
}

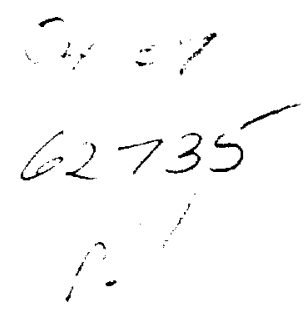

\begin{abstract}
This study examines the response of a flexible rotor supported by load sharing between linear bearings and an auxiliary clearance bearing. The objective of the work is to develop a better understanding of the dynamical behavior of a magnetic bearing supported rotor system interacting with auxiliary bearings during a critical operating condition. Of particular interest is the effect of coupling between the bearing/housing and shaft vibration on the rotordynamical responses. A simulation model is developed and a number of studies are performed for various parametric configurations. An experimental investigation is also conducted to compare and verify the rotordynamic behavior predicted by the simulation studies. A strategy for reducing sychronous shaft vibration through appropriate design of coupled shaft/bearing/housing vibration modes is identified. The results are presented and discussed.
\end{abstract}

\section{NOMENCLATURE}

$C=$ damping, $\mathrm{N}-\mathrm{sec} / \mathrm{m}$

$K=$ stiffness, $\mathrm{N} / \mathrm{m}$

$M_{b}=$ auxiliary bearing mass, $\mathrm{kg}$.

$M_{h}=$ housing mass, $\mathrm{kg}$.

$N=$ total number of modes considered

$N_{b 1}=$ node number at leftmost bearing

$N_{b 2}=$ node number at rightmost bearing

$N_{b 3}=$ node number at auxiliary clearance bearing

$\mathbf{Q}_{x}=$ rotor modal coordinate vector in $\mathrm{X}$ direction

$\mathbf{Q}_{y}=$ rotor modal coordinate vector in $\mathrm{Y}$ direction $t=$ time, $\mathrm{s}$

$X_{r}=$ rotor physical coordinate vector in $\mathrm{X}$ direction, $\mathrm{m}$

$Y_{r}=$ rotor physical coordinate vector in $Y$ direction, $\mathrm{m}$

$X_{b}=$ auxiliary bearing physical coordinate vector in $\mathrm{X}$ direction, $\mathrm{m}$

$Y_{b}=$ auxiliary bearing physical coordinate vector in $\mathrm{Y}$ direction, $\mathrm{m}$

$X_{h}=$ housing physical coordinate vector in $\mathrm{X}$ direction, $m$

$Y_{h}=$ housing physical coordinate vector in $\mathrm{Y}$ direction

$\Delta=$ radial clearance in auxiliary bearing, $\mathrm{m}$

$\mathrm{I}_{a}=$ rotor polar mass inertia matrix, $\mathrm{kg}-\mathrm{m}^{2}$

$\Psi=$ rotor free-free modal rotation matrix

$\Phi=$ rotor free-free modal displacement matrix

$\Gamma=\Psi^{T} I_{a} \Psi$

$\Omega=$ rotor operating speed, $\mathrm{rad} / \mathrm{s}$

$\omega_{n}=$ matrix of rotor free-free natural frequencies, $\mathrm{rad} / \mathrm{s}$

$\psi=$ imbalance vector

Subscripts

$b x=$ auxiliary bearing, $x$-direction

$b y=$ auxiliary bearing, $y$-direction

$c=$ contact

$h x=$ housing, $x$-direction

$h x=$ housing, $\mathrm{y}$-direction

$x r=$ rightmost bearing, $\mathrm{x}$-direction

$x l=$ leftmost bearing, $x$-direction

$y r=$ rightmost bearing, $y$-direction

$y l=$ leftmost bearing, $y$-direction

Presented at the International Gas Turbine and Aeroengine Congress \& Exposition Houston, Texas - June 5-8, 1995

This paper has been accepted for publication in the Transactions of the ASME

Discussion of it will be accepted at ASME Headquarters until September 30, 1995 


\section{INTRODUCTION}

In recent years, the use of active magnetic bearings for supporting turbomachinery has been an area of interest for both academic researchers and turbomachinery users in industry. Magnetic bearings provide the potential for significant improvements over other types of rotor support, including elimination of wear and bearing friction-related energy losses as well as a means of actively suppressing rotor vibration. However, their use has been significantly limited due to a number of technical problems. A particular area of concern is the auxiliary bearing, which protects the soft iron core of the magnetic bearing and provides rotor support in case of overload or failure of the magnetic bearing.

Typically, the auxiliary bearings have relatively small clearances so that magnetic bearing rotor/stator contact does not occur during bearing failure or power loss. Due to these small clearances, contact between the rotor system and the auxiliary bearings can occur during standard operation of the magnetic bearings. When this occurs, load sharing between the magnetic bearings and the auxiliary bearings results, and the rotor system interacts with its auxiliary bearings. The dynamics of such an occurrence must be understood in order to properly design the auxiliary bearing system for a magnetic bearing supported rotor.

A number of different bearing types have been suggested as auxiliary bearings. These include bushings, rolling element bearings, and various types of journal bearings. The most commonly considered are rolling element bearings. The major disadvantage associated with using rolling element bearings (or bushings) is the requirement of a clearance between the rotor and the inner race of the bearing, without which many of the advantages associated with using magnetic bearings would be reduced or eliminated. This clearance introduces a nonlinear dynamical feature which may significantly impact the behavior of the rotor.

There are quite a number of studies in the literature concerned with nonlinear rotordynamics. Ehrich (1965 and 1967) studied the rotor/stator interaction with a clearance and found zones of bistable synchronous behavior. Black (1968) also found these bistable interaction zones. Ehrich extended this research by predicting subharmonic behavior (1966 and 1988), superharmonic behavior (1992), and chaotic responses (1991). Bently (1974), Muszynska (1984), and Childs (1979 and 1982) also observed and studied subharmonic responses due to clearance effects.

There is relatively little work available in the open literature that is specifically concerned with the dynamics between the rotor system and the auxiliary bearings. The research that has been performed to date is primarily concerned with the transient behavior of rotor drop on the auxiliary bearings due to power faliure or inoperative magnetic bearings. Two papers with this focus are Gelin et al., (1990) and Ishii and Kirk (1991).

The present work is concerned with developing an understanding of the dynamic behavior of a rotor system supported by load sharing between the linear bearings and an auxiliary bearing with clearance. Of particular interest is the influence of coupled shaft/bearing/housing vibration modes on the rotordynamical behavior of such a system.

\section{SIMULATION MODEL}

Figure 1 shows the simulation model used for this investigation. It consists of a flexible rotor supported at both ends by magnetic bearings. A rigid disk with adjustable imbalance is placed at the midpoint of the bearing span. As a simplification, the magnetic bearings are modeled as spring and dashpot systems and interaction with a single auxiliary bearing is considered. The auxiliary bearing was modeled as an antifriction bearing with a clearance and a mass attached to a housing. The housing in turn has a mass, stiffness, and damping. Figure 2 shows the auxiliary bearing model used in the simulation.

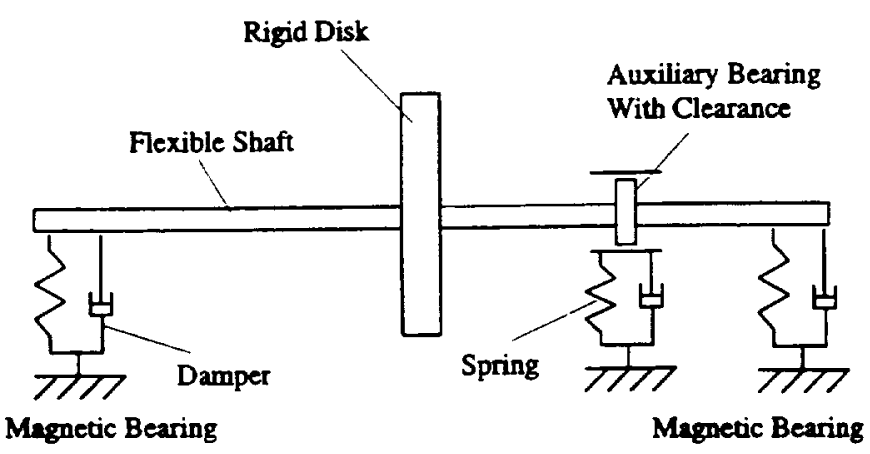

Figure 1 Schematic Diagram of Simulation Model

The rotor is modelled using the free-free bending mode shapes and natural frequencies obtained through finite element analysis. The finite element code uses 19 stations and the first four modes (two rigid body and two flexible modes) are included in the simulation model.

Using these simplifications, the equations of motion for the system can be written as follows:

$$
\ddot{\mathrm{Q}}_{x}+\Omega \Gamma \dot{\mathrm{Q}}_{y}+\omega_{n}^{2} \mathrm{Q}_{x}+\Phi^{T}\left(F_{x, l i n}+F_{x, n l}\right)
$$




$$
\begin{aligned}
& =\Phi^{T} F_{x, i m b}, \\
\ddot{Q}_{y}- & \Omega \Gamma \dot{Q}_{x}+\omega_{n}^{2} \mathbf{Q}_{y}+\Phi^{T}\left(F_{y, l i n}+F_{y, n l}\right) \\
& =\Phi^{T} F_{y, i m b} \\
M_{b} \ddot{X}_{b}+ & \frac{C_{b x}}{\Omega}\left(\dot{X}_{b}-\dot{X}_{h}\right)+K_{b x}\left(X_{b}-X_{h}\right) \\
& =F_{x, n l} \\
M_{b} \ddot{Y}_{b}+ & \frac{C_{b y}}{\Omega}\left(\dot{Y}_{b}-\dot{Y}_{h}\right)+K_{b y}\left(Y_{b}-Y_{h}\right) \\
& =F_{y, n l}, \\
M_{h} \ddot{X}_{h}+ & \left(\frac{C_{b x}}{\Omega}+\frac{C_{h x}}{\Omega}\right) \dot{X}_{h}+\left(K_{b x}+K_{h x}\right) X_{h} \\
& =C_{b x} \dot{X}_{b}+K_{b x} X_{b}, \\
M_{h} \ddot{Y}_{h}+ & \left(\frac{C_{b y}}{\Omega}+\frac{C_{h y}}{\Omega}\right) \dot{Y}_{h}+\left(K_{b y}+K_{h y}\right) Y_{h} \\
& =\frac{C_{b y}}{\Omega} \dot{Y}_{b}+K_{b y} Y_{b},
\end{aligned}
$$

where

$$
\begin{aligned}
\mathbf{F}_{x, l i n} & =\Phi_{N_{b 1}}\left(K_{x l} \mathbf{Q}_{x}+\frac{C_{x l}}{\Omega} \dot{Q}_{x}\right) \\
& +\Phi_{N_{b 2}}\left(K_{x r} \mathbf{Q}_{x}+\frac{C_{x r}}{\Omega} \dot{Q}_{x}\right) \\
\mathbf{F}_{y, l i n}= & \Phi_{N_{b 1}}\left(K_{y l} \mathbf{Q}_{y}+\frac{C_{y l}}{\Omega} \dot{Q}_{y}\right) \\
& +\Phi_{N_{b 2}}\left(K_{y r} \mathbf{Q}_{y}+\frac{C_{y r}}{\Omega} \dot{Q}_{y}\right) \\
\mathbf{F}_{x, i m b}= & \psi \Omega^{2} \cos \Omega t, \\
\mathbf{F}_{y, i m b}= & \psi \Omega^{2} \sin \Omega t, \\
\mathbf{F}_{x, n l}= & \phi K_{c}(\delta-\Delta)\left(\frac{\Phi Q_{x}-X_{b}}{\delta}\right) \\
\mathbf{F}_{y, n l}= & \phi K_{\text {cont }}(\delta-\Delta)\left(\frac{\Phi Q_{y}-Y_{b}}{\delta}\right) \\
\delta= & \sqrt{\left(\Phi \mathbf{Q}_{x}-X_{b}\right)^{2}+\left(\Phi \mathbf{Q}_{y}-Y_{b}\right)^{2}}, \\
\phi= & 1 \text { if } \delta>\Delta \\
& 0 \text { otherwise } \\
\mathbf{Q}_{x}= & \Phi^{-1} \mathrm{X}_{r}, \\
\mathbf{Q}_{y}= & \Phi^{-1} \mathrm{Y}_{r},
\end{aligned}
$$

with

$$
\begin{aligned}
& \mathbf{X}_{r}=\left\{X_{r 1}, X_{r 2}, \ldots, X_{r m}\right\}^{T} \\
& \mathbf{Y}_{r}=\left\{Y_{r 1}, Y_{r 2}, \ldots, Y_{r m}\right\}^{T} \\
& (m=\text { total number of nodes) }
\end{aligned}
$$

The physical displacements of the rotor at the auxiliary bearing or magnetic bearing locations can be obtained using the following coordinate transformation:

$$
\begin{aligned}
& X_{r k}=\sum_{i=1}^{N} \Phi_{k i} Q_{x i} \\
& Y_{r k}=\sum_{i=1}^{N} \Phi_{k i} Q_{y i}
\end{aligned}
$$

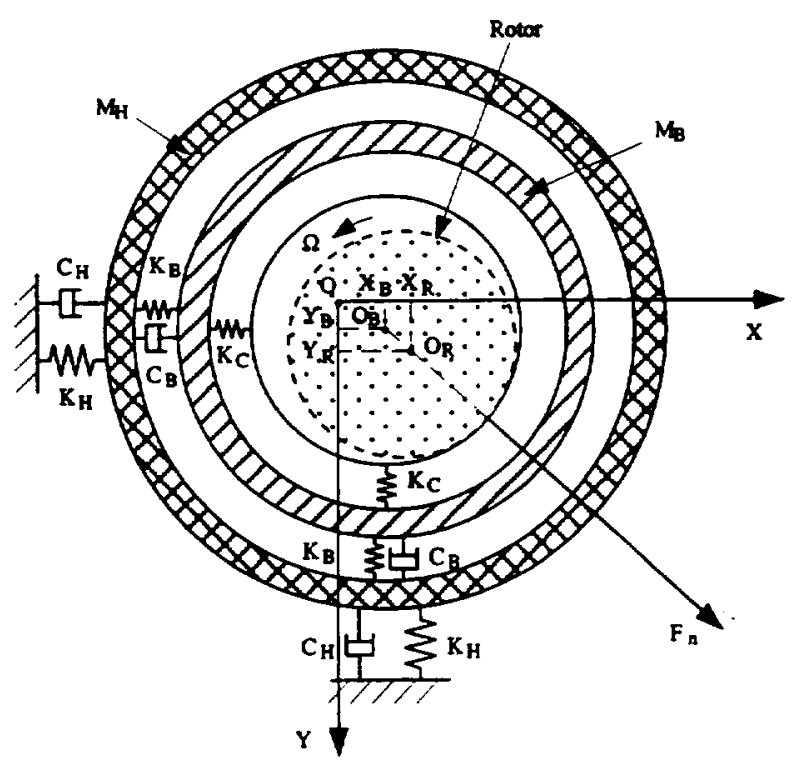

Figure 2 Auxiliary Bearing Model

\section{EXPERIMENTAL MODEL}

Experimental tests were performed in order to validate the behavior predicted by the simulation model and to gain some insight into the dynamical responses that are to be expected. A schematic diagram of the rotor test rig that was used in the experimental work is shown in Figure 3.

The rotor used in this study has two basic components: a flexible shaft and an auxiliary clearance bearing. The shaft is made of steel and is 0.374 inches in diameter and 18.0 inches in length. It is supported at 1.0 inch from the right end by ball bearings suspended in a frame by four springs and at 1.0 inch from the left end by a bushing with a tight clearance. These supports 


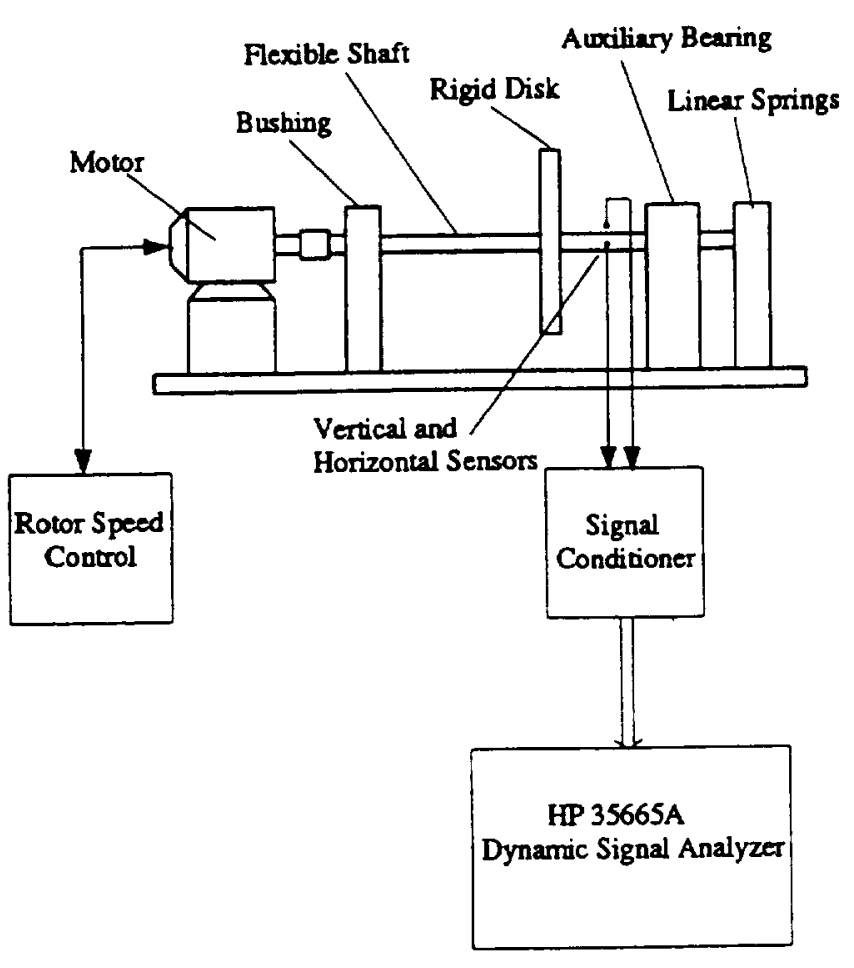

Figure 3 Experimental Model

represent the magnetic bearings. The stiffness of the left support is $17511 \mathrm{~N} / \mathrm{m}(101.5 \mathrm{lb} / \mathrm{in})$ for both the horizontal and vertical directions. It is used to somewhat isolate the rotor from the effects of the flexible coupling which attaches the rotor to the motor and to enforce low amplitude vibration at this location to protect the motor. The stiffness of the right support, for both horizontal and vertical directions, is $2539 \mathrm{~N} / \mathrm{m}(14.5 \mathrm{lb} / \mathrm{in})$. This lower stiffness allows for significant vibration of the rotor in the speed range of the motor. A rigid disk with an adjustable imbalance is placed at the midpoint of the bearing span. The auxiliary clearance bearing/housing consists of a bushing suspended in a frame by four springs (Figure 4). It is situated at the right end of the rotor. The clearance is adjustable by changing the bushing. The auxiliary bearing/housing stiffnesses are varied by interchanging the springs.

The rotor is driven by an adjustable speed motor with feedback speed controller. Shaft vibration is measured using eddy current proximity displacement sensors fixed so as to measure displacement in the vertical and horizontal directions. The displacement signals were recorded and analyzed with a signal analyzer.

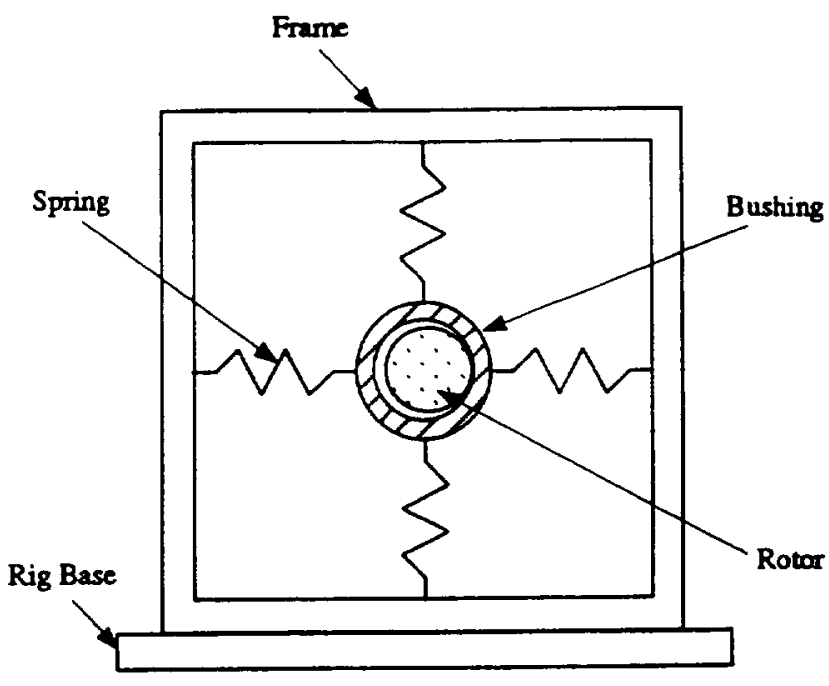

Figure 4 Auxiliary Clearance Bearing

\section{DISCUSSION}

A series of parallel studies were conducted using the simulation and experimental models discussed in the preceding sections. The following discussion is aimed at comparing the predictions of the simulation model with experimentally observed responses, with the objective of obtaining insight into the behavior of flexible rotor system dynamics due to load sharing between the magnetic bearings and an auxiliary bearing.

Using the data from measurements and calculations, the stiffness, damping, and mass characteristics of the experimental rotor system were identified. The imbalance configuration consists of $3.0 \mathrm{x}$ $10^{-6} \mathrm{~kg}-\mathrm{m}$ located at the left end of the rotor shaft (from the flexible coupling to the electric motor) and a variable imbalance located on the rigid disk. Linear, hysteretic, and coulomb friction damping models were considered. The support damping appears to result principally from hysteresis. If synchronous vibration is assumed, this results in a damping coefficient scaled by the rotor speed. The numerical values are given in Table 1 .

The governing parameters for an auxiliary bearing are stiffness, mass, damping, clearance, and axial location. The axial location generally is fixed by other considerations, such as space requirements and the need to be close to the magnetic bearing to better protect it. This study focusses on the remaining design parameters. For the system studied, significant nonsynchronous vibration occured only for the $2 \omega$ component and for a limited rotor speed range. Figure 5 illustrates the observed behavior for various imbalance values. The amplitudes are quite small and, interestingly, virtually independent of imbalance. The remainder of this discussion will focus on the synchronous response amplitudes. 


\begin{tabular}{|r|r|r|}
\hline Parameter & Value & Units \\
\hline $\mathrm{K}_{\mathrm{b}}$ & 471 & $\mathrm{~N} / \mathrm{m}$ \\
\hline $\mathrm{K}_{\mathrm{h}}$ & $1.8 \times 10^{7}$ & $\mathrm{~N} / \mathrm{m}$ \\
\hline $\mathrm{K}_{\mathrm{c}}$ & 87,557 & $\mathrm{~N} / \mathrm{m}$ \\
\hline $\mathrm{K}_{\mathrm{lx}}, \mathrm{K}_{\mathrm{ly}}$ & 17,510 & $\mathrm{~N} / \mathrm{m}$ \\
\hline $\mathrm{K}_{\mathrm{rx}}, \mathrm{K}_{\mathrm{ry}}$ & 2,539 & $\mathrm{~N} / \mathrm{m}$ \\
\hline $\mathrm{C}_{\mathrm{lx}}, \mathrm{C}_{\mathrm{ly}}$ & 1,000 & $\mathrm{~N} / \mathrm{m}$ \\
\hline $\mathrm{C}_{\mathrm{rx}}, \mathrm{C}_{\mathrm{ry}}$ & 500 & $\mathrm{~N} / \mathrm{m}$ \\
\hline $\mathrm{C}_{\mathrm{ly}}, \mathrm{C}_{\mathrm{ly}}$ & 1,000 & $\mathrm{~N} / \mathrm{m}$ \\
\hline $\mathrm{C}_{\mathrm{ry}}, \mathrm{C}_{\mathrm{ry}}$ & 500 & $\mathrm{~N} / \mathrm{m}$ \\
\hline $\mathrm{C}_{\mathrm{bx}}, \mathrm{C}_{\mathrm{by}}$ & 2,000 & $\mathrm{~N} / \mathrm{m}$ \\
\hline $\mathrm{C}_{\mathrm{hx}}, \mathrm{C}_{\mathrm{hy}}$ & 0 & $\mathrm{~N} / \mathrm{m}$ \\
\hline $\mathrm{M}_{\mathrm{b}}$ & 0.033 & $\mathrm{~kg}$ \\
\hline $\mathrm{M}_{\mathrm{h}}$ & 0.296 & $\mathrm{~kg}$ \\
\hline$\psi_{1}$ & $3.0 \times 10^{-6}$ & $\mathrm{~kg}-\mathrm{m}$ \\
\hline$\psi_{10}$ & $2.5 \times 10^{-5}$ & $\mathrm{~kg}-\mathrm{m}$ \\
\hline$\Delta$ & $5.0 \times 10^{-5}$ & $\mathrm{~m}$ \\
\hline
\end{tabular}

Table 1 Simulation Model Parameters

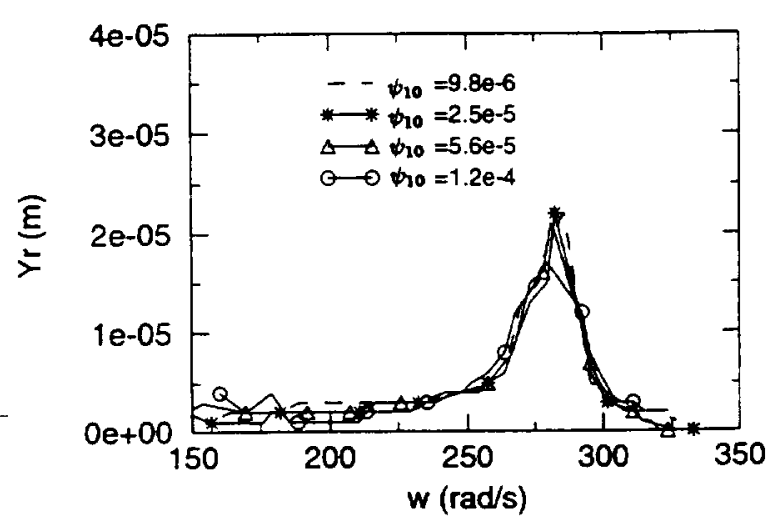

Figure 5 Experimental Results for $2 \omega$ Component

The simulation responses discussed below were determined from a single-term harmonic balance analysis that was numerically implemented and verified at selected points using direct numerical integration of the governing equations of motion. The harmonic balance procedure is described by Nayfeh and Mook (1979). Figures 6.a - 6.e show the response amplitudes predicted from the simulation study for the parameters of Table 1. Figures T.a 7.c show some corresponding experimental results. The rotor speed range extends to above the second critical speed, with the first critical speed primar- ily a rotational mode and the second critical speed primarily a translational mode.

Figures 6.a presents simulation results for varying auxiliary bearing stiffness and Figure 7.a shows the corresponding experimental values. There is relatively good agreement between the actual and predicted responses except for the peak values which are very sensitive to damping. At lower rotor speeds, the stiffness effect from the auxiliary bearing tends to dominate and serves to increase the effective lower critical speed. At higher rotor speeds, the inertial effects of the bearing tend to dominate and the added mass serves to lower the effective second critical speed. This effect is balanced somewhat for higher stiffnesses (as is expected), as can be seen for the case with $K_{b}=2,625$ $\mathrm{N} / \mathrm{m}$. The damping added to the system from the auxiliary bearing serves to attenuate the peak response amplitudes for both critical speeds. The response amplitudes between the two response peaks are affected little by the auxiliary bearing, with the rotor and bearing/housing vibrations tending to decouple for response amplitudes below the clearance. Above the second critical speed, the presence of the auxiliary bearing serves to reduce the response amplitudes for the remainder of the plot. For this region, there is significant coupling between the rotor/bearing/housing vibration and the response amplitudes are below the clearance for speeds greater than about $550 \mathrm{rad} / \mathrm{sec}$. The rotor speed ranges for which coupling of the rotor/bearing/housing vibration will occur depend upon the phase of the combined system response, as described by Black (1968). For the purposes of this study, $K_{b}=471 \mathrm{~N} / \mathrm{m}$ is chosen as a reasonable value and variations of other parameters are performed with this auxiliary bearing stiffness.

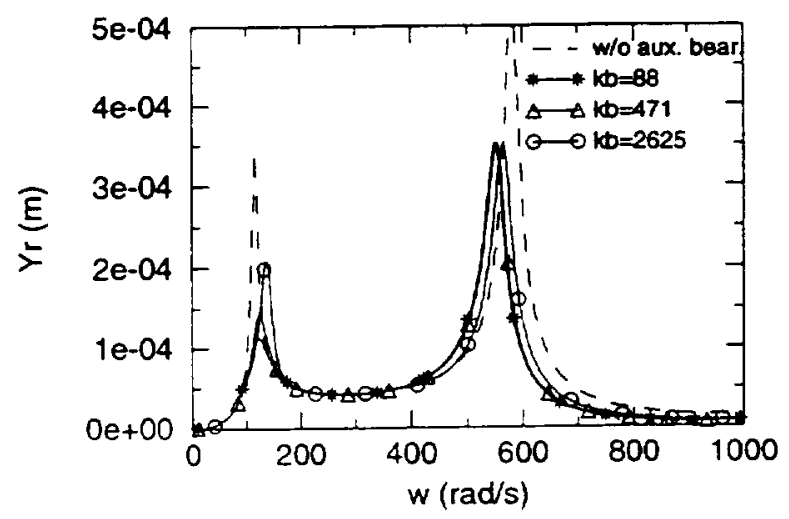

Figure 6.a Simulation Results for Varying Auxiliary Bearing Stiffness 


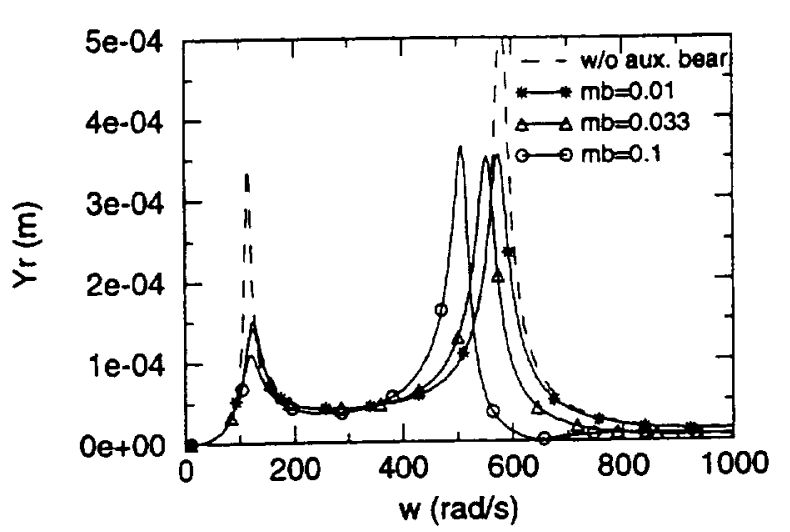

Figure 6.b Simulation Results for Varying Auxiliary Bearing Mass

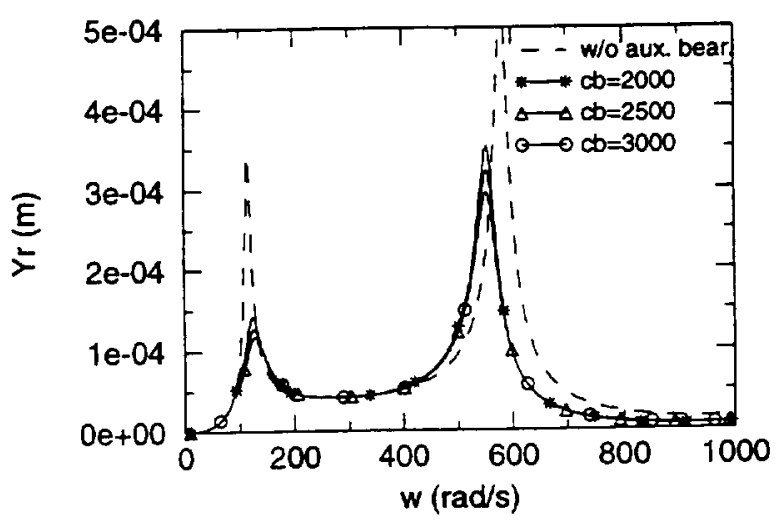
Figure 6.c Simulation Results for Varying
Auxiliary Bearing Damping

Figures 6.b shows the predicted rotor response for the parameters of Table 1 with the bearing mass varied. These results show that the more massive bearing/housing configurations can result in much lower amplitude rotor responses. In fact, for sufficiently high mass values, the response amplitude is dramatically reduced for the rotor speed range from about $600 \mathrm{rad} / \mathrm{sec}$ to about $780 \mathrm{rad} / \mathrm{sec}$ where it merges with other amplitude response curves. Figure 6.C shows the effect of auxiliary bearing damping on the rotor response. While the response amplitudes remain relatively unchanged for the majority of rotor speeds, higher damping does serve to significantly reduce the rotor response amplitudes through the critical speeds. Damping also effects the phase characteristics of the combined rotor/bearing/housing system and changes the ro-

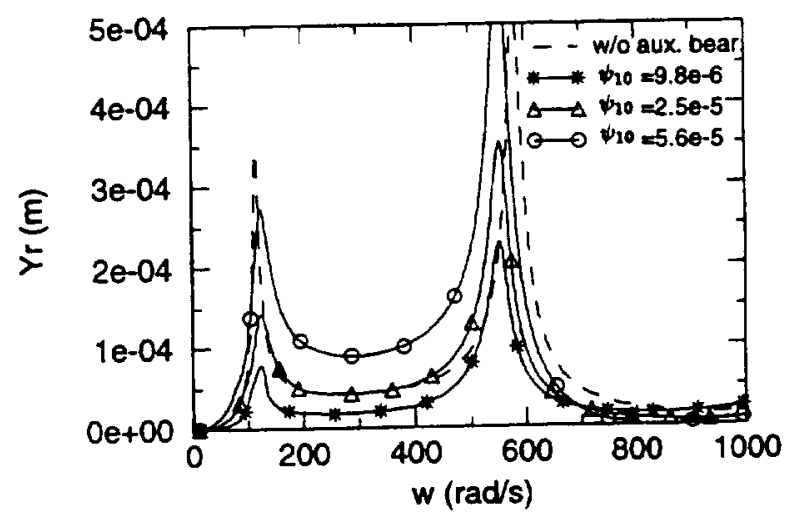
Figure 6.d Simulation Results for Varying

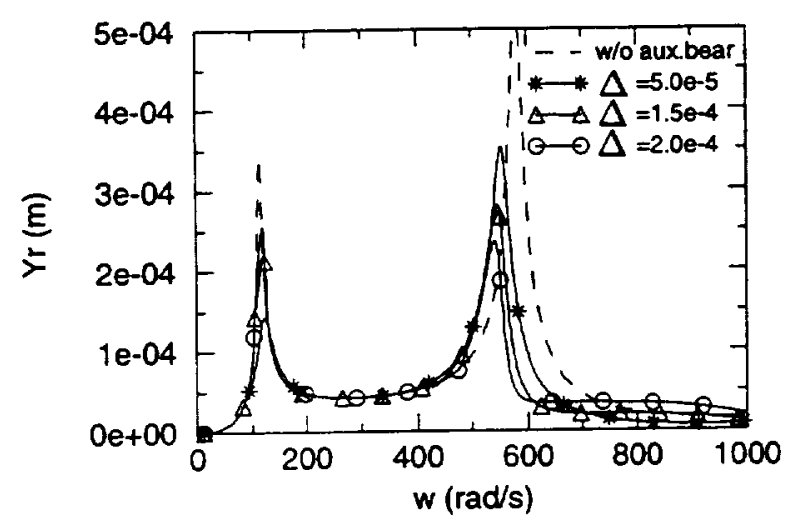

Figure 6.e Simulation Results for Varying Auxiliary Bearing Clearance

tor speed ranges for which coupled responses occur. Figures 6.d and 7.b show the rotor response for the parameters of Table 1 with the imbalance varied. As expected, the response amplitudes increase with increasing imbalance. Figures 6.e and 7.c show the rotor response amplitudes with the auxiliary bear. ing clearance varied. As the clearance increases, the dynamics of the combined rotor/bearing/housing vibration tend to decouple over a wider speed range between the two critical speeds. Again, such behavior is expected from the analysis work for a rotor operating in an annular clearance performed by Black (1968).

Close examination of the above results reveals a very interesting trend. Turbomachine are designed to operate at rotor speeds between the various system critical speeds so as to minimize synchronous 


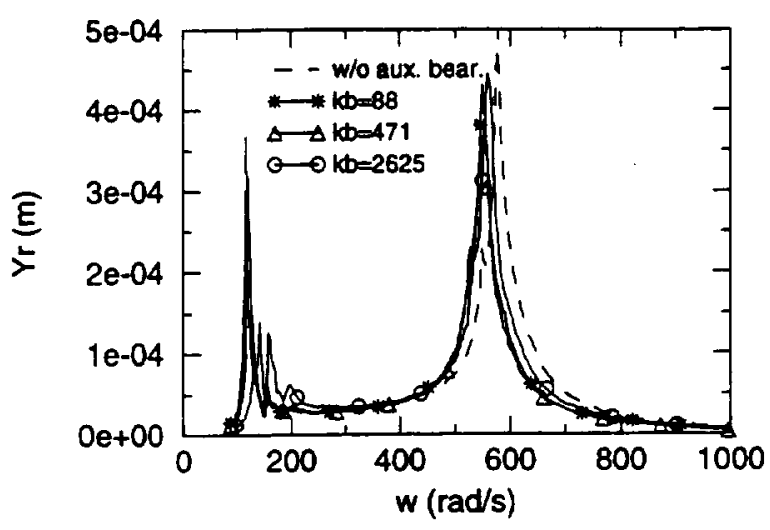

Figure 7.a Experimental Results for Varying Auxiliary Bearing Stiffness

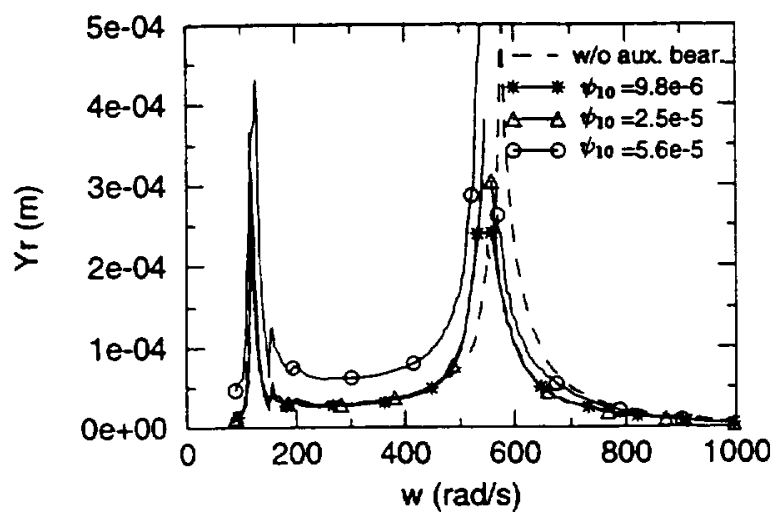

- Figure 7.b Experimental Results for Varying Imbalance

response amplitudes. For the present system, the lowest amplitude responses (for operation above the second critical speed) occur for the auxiliary bearing configurations where there is the largest decrease of the second effective critical speed, which is due to a coupling of rotor/stator/housing vibration. While not really suprising, this result indicates an interesting strategy for the design of auxiliary support using clearance bearings. Selection of combined shaft/auxiliary bearing/housing vibration characteristics such that the effective critical speeds nearest the operating speed (directly above and below) shift away from it should result in lower amplitude rotor vibration and provide the best opportunity to protect the magnetic bearing. However, the phase characteristics of the combined system must be such that vibration coupling occurs

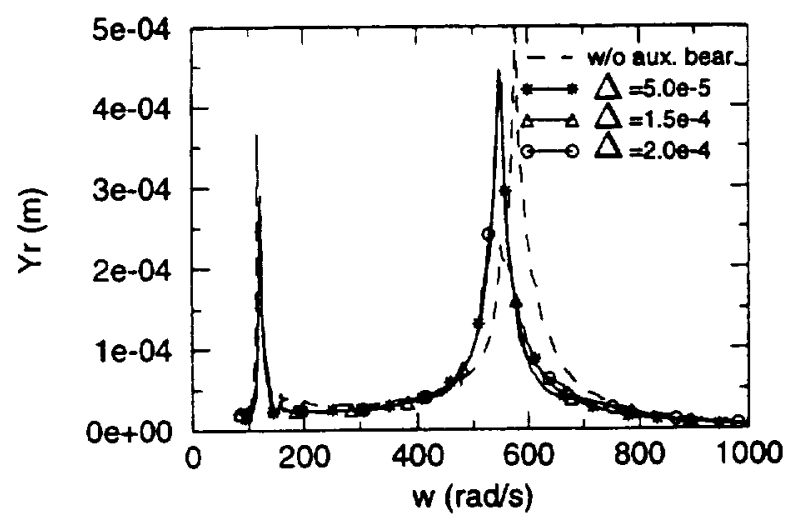

Figure 7.c Experimental Results for Varying Auxiliary Bearing Clearance

and care must be taken to ensure that this is the case if the maximum benefit is to be derived from the auxiliary bearing.

\section{CONCLUSIONS}

A study of the dynamical behavior of a flexible rotor supported by linear bearings (representing a set of magnetic bearings) and an auxiliary bearing with clearance has been presented. Parallel simulation and experimental studies have been performed for a variety of parametric configurations. The influence of bearing mass, stiffness, damping, clearance, and imbalance were examined. It was observed that the dynamic behavior of a rotor interacting with an auxiliary bearing depends very strongly on the structural parameters of the auxiliary bearing and associated housing. Appropriate selection of these parameters is critical if acceptable vibration characteristics are to be obtained for such systems. In general, one must carefully consider the influence of housing/bearing dynamics and how to best take advantage of favorable coupled modes of vibration in the development of auxiliary bearing designs.

\section{ACKNOWLEDGEMENT}

This work was supported by NASA under Grant No. NGT-70312 and Grant No. NAG3-1507. The Government has certain rights in this material. Appreciation is expressed to S.C. Sinha, S.G. Ryan and A.F. Kascak for their advice and assistance in this research effort. 


\section{REFERENCES}

Bently, D. E., 1974, "Forced Subrotative Speed Dynamic Action of Rotating Machinery," ASME Paper No. 74-PET-16.

Black, H. F., 1968, "Interaction of a Whirling Rotor With a Vibrating Stator Across a Clearance Annulus," Journal Mechanical Engineering Science, Vol. 10, No 1, pp. 1-12.

Childs, D. W., 1979, "Rub-Induced Parametric Excitation in Rotors," ASME Journal of Mechanical Design, Vol. 101, pp. 640-644.

Childs, D. W., 1982, "Fractional-Frequency Rotor Motion Due to Nonsymmetirc Clearance Effects," ASME Journal of Engineering for Power, Vol. 104, pp. 533-541.

Ehrich, F. F., 1965, "Bistable Vibrations of Rotors in Bearing Clearance," ASME Paper 65WA/MD-1.

Ehrich, F. F., 1988, "High Order Subharmonic Response of High Speed Rotors in Bearing Clearance," ASME Journal of Vibration, Acoustics, Stress, and Reliability in Design, Vol. 110, pp. 9-16.

Ehrich, F. F., 1992, "Observatons of Subcritical Superharmonic and Chaotic Response in Rotordynamics," ASME Journal of Vibration and Acoustics, Vol. 114, pp. 93-100.

Ehrich, F. F., 1991, "Some Observatons of Chaotic Vibration Phenonema in High-speed Rotordynamics," ASME Journal of Vibration, Acoustics, Stress, and Reliability in Design, Vol. 113 , pp. 50-57.

Ehrich, F. F., 1966, "Subharmonic Vibration of Rotors in a Bearing Clearance," ASME Paper 66-MD-1.

Ehrich, F. F., and O'Conner, J. J., 1967, "Stator Whirl with Rotors in Bearing Clearance," ASME Journal of Engineering for Industry, August, pp. 381-390.

Gelin, Al, Pugnet, J. M., and Hagopina, J. D., 1990, "Dynamic Behavior of Flexible Rotors with Active Magnetic Bearings of Safety Auxiliary Bearings," Proceedings of 3rd International Conference on Rotordynamics, Lyon, France, pp. 503-508.

Ishii, T., and Kirk, R. G., 1991, "Transient Response Technique Applied to Active Magnetic Bearing Machinery During Rotor Drop," $D E$ Vol. 35, Rotating Machinery and Vehicle Dynamics, ASME, pp. 191-199.

Muszynska, A., 1984, "Partial Lateral Rotor to Stator Rubs," IMechE Paper No. C281/84.
Nayfeh, A.H., and Mook, D.T., 1979, Nonlinear Oscillations, John Wiley and Sons, pp. 59-61.

Ryan, S.G., 1991, "Limit Cycle Vibrations in Turbomachinery," NASA Technical Paper 3181. 
